\title{
EXPERIENCES MATTER: EDUCATORS' ATTITUDES TOWARD DISABILITY IN HIGHER EDUCATION
}

\author{
JOHNFREER \\ ST. CLAIR COLLEGE \& UNIVERSITY OF WINDSOR \\ TANYA KAEFER \\ LAKEHEAD UNIVERSITY
}

\begin{abstract}
This study investigated 128 post-secondary educators' attitudes toward disability at a college and a university in southwestern Ontario, Canada. The participants completed the Educators' Attitudes toward Disability Scale (EADS) and a demographic questionnaire that included questions about their experiences with disability. There were three research questions at the heart of this study: (1) What are post-secondary educators' overall attitudes toward disability? (2) Do demographic factors predict post-secondary educators' attitudes toward disability? (3) Does exposure to people with disability predict post-secondary educators' attitudes toward disability? The findings of this study suggest post-secondary educators hold overall positive attitudes toward disability and there were very few differences observed between groups (e.g., based on age, gender, discipline, etc.). Educators' experiences with people who have a disability, however, were positively associated with their attitudes. This factor included personal experiences (e.g., friends, family, etc.), but also professional experiences (e.g., students in their classes).
\end{abstract}

Keywords: disability, attitude, professors, post-secondary, determinant factors, experience

\section{Résumé}

Cette étude examine l'attitude de 128 enseignants à l'égard du handicap dans un collège et une université du sud-ouest de I'Ontario, au Canada. Les participants ont rempli le Educators Attitudes toward Disability Scale (EADS) et un questionnaire démographique incluant des questions au sujet de leurs expériences avec le handicap. Trois questions de recherche ont été soulevées : (1) Quelle est l'attitude générale des enseignants d'établissements postsecondaires à l'égard du handicap? (2) Les facteurs démographiques ont-ils une incidence sur l'attitude des enseignants d'établissements postsecondaires à l'égard du handicap? (3) L'exposition à des personnes en situation de handicap a-t-elle une incidence sur l'attitude des enseignants d'établissements postsecondaires à l'égard du handicap? Les résultats de cette étude suggèrent que les enseignants du secteur postsecondaire ont une attitude généralement positive à l'égard des personnes en situation de handicap, et très peu de différences ont été observées entre les groupes (p. ex. sur la base de l'âge, du sexe, de la discipline, etc.). Cependant, l'expérience avec des personnes en situation de handicap avait une incidence positive sur les attitudes. Ce facteur comprenait les expériences personnelles (p. ex. amis, famille, etc.) et l'expérience professionnelle (p. ex. étudiants).

Mots-clés : handicap, attitude, enseignants, postsecondaire, facteurs déterminants, expérience

\section{Introduction}

The successful completion of post-secondary education has long been touted as a key to economic security. According to Statistics Canada, having a post-secondary education is associated with lower unemployment and higher earnings compared to those without a college or university education, although one's chosen field of study also has an impact on income potential (Ostrovsky \& Frenette, 2015). In addition, people with disabilities tend to have higher rates of unemployment compared to people without disabilities, but this difference is considerably lower for those with a post-secondary education (particularly among those with mild impairments; Tur- 
cotte, 2014). Recently, strategies have been put in place to make higher education more accessible for people with disabilities (e.g., bursaries, transition planning, etc.). These efforts have resulted in more students with disabilities than ever before attending post-secondary institutions (McCloy \& DeClou, 2013).

Those students with disabilities who register with disability service offices often have specified accommodation plans to help meet their academic needs (National Educational Association of Disabled Students [NEADS], 2012). At the post-secondary level, students' work can be accommodated, while modifications to curriculum are not typically permitted. Accommodation plans might include instructional (e.g., a notetaker), environmental (e.g., preferential seating), and/or assessment accommodations (e.g., extensions on assignments), and may also outline the need for assistive technologies. Studies have reported that between $2 \%$ and $13 \%$ of students register for support with disability service offices, with a higher rate at colleges than universities (Fichten et al., 2003; Harrison \& Wolforth, 2012; Tsagris \& Muirhead, 2012). Most of these students have invisible or hidden disabilities (e.g., learning disabilities; Fichten et al., 2003; Harrison \& Wolforth, 2012). Despite more students being accommodated, many students with disabilities continue to report barriers to access, which in some cases can impact program completion (Carroll et al., 2020; Kutscher \& Tuckwiller, 2019).

There are a variety of barriers that students with disabilities face in post-secondary education (e.g., institutional, attitudinal, etc.). As a result, an accessibility standard for the post-secondary education sector is currently being developed under the Accessibility for Ontarian with Disabilities Act (AODA; AODA Alliance, 2020). Breaking down barriers to post-secondary education will also help to reduce the barriers people with disabilities experience in the employment sector (AODA Alliance, 2020).

One of the types of barriers outlined in the draft of the accessibility standard for post-secondary education is attitudinal barriers (AODA Alliance, 2020). Attitudinal barriers are especially powerful because they can often be at the root of other barriers. For example, poor attitudes toward disability could result in an institutional policy that unjustly disadvantages students with exceptionalities. Both the Ontario Human Rights Commission (n.d.) and the NEADS (2018) have pointed out that post-secondary students with disabilities sometimes face ableist attitudes from their professors. For example, instructors may inappropriately ask their students to self-disclose the nature of their disability or ask a student to provide them with medical documentation. Students who present their accommodation plans to their instructors have already gone through the appropriate channels to receive supports and have a right to their privacy and their accommodations. Professors' attitudes toward disability can impact the inclusion or exclusion of students with disabilities in colleges and universities, especially given their position of authority (Duquette, 2000). The goal of the current study was to examine professors' attitudes and how they may be impacted by demographic factors, as well as experiences with disability.

\section{Theoretical Frameworks}

The two concepts central to this study are attitude and disability. Below we discuss the theoretical frameworks utilized for each of these two concepts.

\section{Attitude}

Attitude is a concept from social psychology that has been studied extensively since the establishment of the discipline. Although many theories of attitude exist, including unidimensional (Fishbein, 1963; Zajonc, 1980) and multidimensional definitions (Triandis, 1971), for the purposes of this study, attitude is operationalized as a unidimensional construct. A factor analysis of the Educators' Attitudes toward Disability Scale (EADS; i.e., the scale used to measure attitude in this study) indicated that the 21-item metric measures attitude as a single factor (Freer, 2018). The relationship between attitudes and behaviour is complex, but the theories of cognitive dissonance and planned behaviour offer some explanation. The theory of cognitive dissonance suggests that people strive for consistency between their attitudes and their actions, but may hold inconsistencies at times (Festinger, 1957). The theory of planned behaviour (Ajzen, 1985, 2001) further explains that attitude does not predict behaviour on its own, citing perceived behavioural control and subjective norms as additional factors.

\section{Disability}

Disability studies scholars who subscribe to the social model argue that disability is a social construction based 
upon barriers present in society (Oliver, 1996). This theory is in opposition to the traditional medical model, which presents disability as an abnormality that needs to be fixed. Once it is acknowledged that disability is, at least in part, a social construction, then consideration can be given to the removal of barriers. This revelation in the way disability is understood has led to progressive legislation aimed at removing barriers from society (e.g., the AODA, the Americans with Disabilities Act, etc.). People with disabilities continue to face barriers in both education and employment (AODA Alliance, 2020). This study focuses on attitudinal barriers in post-secondary education and therefore the social model is an appropriate theoretical framework for this study.

\section{Literature Review}

Professors' attitudes toward their students with disabilities can serve to be a facilitating factor for student success or pose a barrier (Duquette, 2000). In the literature on this topic, there are some different approaches to the question of faculty's attitudes toward disability. Some scholars in this field have examined students' perspectives of their professors' attitudes (Dowrick et al., 2005; Francis et al., 2019). Others have investigated post-secondary educators' attitudes toward disability, as reported by the faculty members themselves, as we have in this study (Sniatecki et al., 2015; Stampoltzis et al., 2015; Wynants \& Dennis, 2017). Another facet of this field of literature includes studies that have examined professors' views of educational practices that relate to their students with disabilities. For example, several studies have looked at faculty members' willingness to accommodate their students with special education needs (Jensen et al., 2004; Ko0, 2017). Others have examined professors' attitudes toward inclusion or universal design for learning (UDL; Gawronski et al., 2016; Lombardi et al., 2013). Theoretically, a faculty's willingness to accommodate or implement inclusive education strategies should be correlated with their attitudes toward disability. In fact, measures of educators' attitudes toward disability often include items and/or subscales related to these educational practices (Hansen et al., 2017; Lombardi \& Murray, 2011; Freer, 2018).

Generally, faculty report positive attitudes toward disability (Lombardi \& Murray, 2011; Sniatecki et al., 2015; Stampoltzis et al., 2015). Although, the extent to which this is driven by social desirability is unknown. In addition, quantitative attitude scores may not tell the whole story. For example, Hansen and Dawson (2020) found that professors expressed concerns about their readiness to teach college students with disabilities, despite reporting positive attitude scores (Hansen et al., 2017).

Researchers have also investigated attitudes toward different disabilities. For example, researchers have examined professors' attitudes toward dyslexia (Stampoltzis et al., 2015), attention-deficit hyperactivity disorder (Buchanan et al., 2010), and learning disabilities (Hansen et al., 2017). Some have also examined post-secondary teachers' attitudes toward disability categories. For example, Sniatecki and colleagues (2015) found that professors tended to hold more favourable attitudes toward physical disabilities compared to mental health disorders and learning disabilities. Generally, people tend to have an easier time accepting disabilities that are more obvious (e.g., physical disabilities), a pattern which seems to emerge at young ages (de Boer et al., 2012; Freer, 2021). While some researchers have examined specific disabilities or disability categories, others have investigated instructors' attitudes toward disability as a general construct (Freer, 2018; Lombardi \& Murray, 2011).

Another aspect of this field of research is intervention studies. Some scholars have been engaged in intervention research aimed at improving professors' attitudes toward disability. Researchers have found that training helps to enhance instructors' attitudes, resulting in a call for more training related to the support of post-secondary students with disabilities (Lombardi \& Murray, 2011). For example, Wynants and Dennis (2017) found that "participating in online professional development led to increased faculty knowledge, improved faculty attitudes, and the emergence of faculty confidence in applying UDI [Universal Design for Instruction] principles for better accessibility of course materials and content presentation" (p. 33).

There also seems to be some variability in educators' attitudes based on demographic factors (e.g., discipline, gender, rank, etc.; Lombardi \& Murray, 2011; Rao, 2004). For example, faculty in education are more likely to hold positive attitudes compared to other fields of study (Lombardi \& Murray, 2011; Skinner, 2007). Levey (2014) reviewed nursing professors' attitudes toward disability and suggested their attitudes may be influenced by 
the medical model of disability, given their professional background. Buchanan and colleagues (2010) examined age as a determinant of faculty's attitudes toward disability. They found that older faculty had more positive attitudes toward students with disabilities compared to middle-aged and younger faculty members (Buchanan et al., 2010). However, others who have looked at age/ years of service have not replicated the same findings. For example, Hansen and colleagues (2017) found no significant differences between early-career, mid-career, and late-career faculty members' attitudes toward disability. On the other hand, many studies have shown that female faculty have more positive attitudes towards disability than male faculty members (e.g. Leyser et al., 1998; Lombardi \& Murray, 2011; Lombardi et al., 2013). This correlation is another one that can be observed early on (de Boer et al., 2012; Freer, 2021).

Additionally, some research suggests that experience teaching students with a disability may be correlated with more positive attitudes toward disability, suggesting that professional experiences may influence attitudes (Rao, 2004). However, personal connections to disability have been studied less often. In the available research, few faculty members reported a personal contact with disability (Leyser et al., 1998), making it hard to examine this factor as a predictor. However, it may be that more current research would reveal more faculty members with such a connection.

Developing a better understanding of the factors associated with professors' attitudes toward disability and the types of experiences that can positively influence attitudes will play an important role in the understanding of attitudinal barriers to student success. The current study aims to explore these connections by examining the influence of both demographic factors and experience with disability (i.e., personal and professional) on attitudes toward disability. To that end, we address the following three research questions:

(1) What are post-secondary educators' overall attitudes toward disability?

(2) Do demographic factors predict post-secondary educators' attitudes toward disability?

(3) Does exposure to people with disability predict post-secondary educators' attitudes toward disability?

\section{Method}

In this section, we discuss the procedure, instruments, sample, and strategies for data analysis.

\section{Procedure}

Faculty members were recruited to participate in this study from one publicly funded college and one publicly funded university in southwestern Ontario, Canada. After receiving Research Ethics Board clearance at both institutions, part-time and full-time professors were recruited by email. Potential participants were sent two recruitment emails, one in April and one in July. The participants were asked to complete an online version of the EADS (Freer, 2018) and a brief demographic questionnaire on Fluid Surveys. A total of 128 post-secondary educators participated in the study. The dataset used for this analysis was part of a larger research project aimed at the psychometric validation of the EADS (Freer, 2018).

\section{Instruments}

Prior to completing the EADS (described below), participants were prompted with instructions and provided with a definition of the term disability. This definition was taken from the AODA.

\section{EADS}

The EADS is a unidimensional assessment of educators' attitudes toward disability. This scale consists of 21 items that are specific to the profession of teaching (e.g., I actively seek opportunities to assist students with disabilities). Some of the EADS items are reverse coded (e.g., teaching students with disabilities takes up a disproportionate amount of time I could use to help other students). Participants indicate their level of agreement or disagreement to each statement using a 6-point Likert scale. Freer (2018) found this scale to be initially valid, while acknowledging the need for replication studies. Additionally, the EADS has been adopted by other scholars interested in educators' attitudes toward disability (e.g., Malone, 2021).

\section{Demographic Questionnaire}

Participants were asked to provide their age, gender, institution, employment status (i.e., part-time or full-time), academic discipline, and years of teaching experience. 
In addition, there were a few questions about the professors' experiences with disability. The participants were asked if they had a close friend or family member with a disability, how often they had taught students with disabilities (i.e., on accommodation plans), and if they were familiar with the policies and mandates in the AODA.

\section{Sample}

The sample for this study consisted of 128 post-secondary educators from two higher education institutions in southwestern Ontario, Canada. The majority of the participants were female (approximately $70 \%$ ), and the ages of participants ranged from 24 to 69 , with an average of 49.26 years-old $(S D=10.99)$. Nearly half of the participants were from the university (i.e., 63) and a little more than half were from the college (i.e., 65). The breakdown between part-time and full-time participants at the two institutions followed a similar split. The college had 21 part-time and 44 full-time college instructors participate. The university had 20 part-time and 43 full-time university instructors participate. Across both institutions, $42 \%$ of respondents reported a discipline within the arts, humanities, or social sciences; $40 \%$ reported a discipline within engineering, sciences, or health sciences; and $18 \%$ reported a discipline within a professional school (e.g., law school, skilled trades, etc.). Years of experience ranged from 1-46, with an average of 13.7 (SD = 9.94). See Table 1 for full breakdown of sample.

\section{Data Analysis}

All statistical analyses were conducted using SPSS v. 26. Descriptive statistics and normality tests were completed to examine the professors' attitudes toward disability. Pearson correlations and independent samples $t$-tests were used to examine the relationship between demographic variables and EADS scores. The relationship between exposure to people with disability and educators' attitudes toward disability were examined using hierarchical regression. The distribution for the EADS scores showed a mild level of skew (skew $=-.64$ ) and approximately normal kurtosis (kurtosis $=.01$ ). All analyses used were robust to this level of skew (Blanca et al., 2017), therefore no further transformations were conducted.

\section{Results}

Next, we discuss the findings of this study in the context of the three research questions presented above.

\section{What are post-secondary educators' overall attitudes toward disability?}

In order to address this question, we examined overall scores on the EADS. We found that out of a possible six points, the average overall score was 5.22 , with a standard deviation of .46. This finding indicates a very positive overall attitude toward disability across the sample.

\section{Do demographic factors predict post-secondary educators' attitudes toward disability?}

We found no significant differences based on any demographic variable measured in the survey. Age was not significantly correlated with EADS score $(r=.08 ; p$ $=.373)$, nor was years of experience $(r=.11 ; p=.218)$. There were no group differences based on gender $(t(125)=.70, p=.485)$, full-time vs. part-time employment $(t(126)=1.60, p=.112)$, or college- vs. university-level employment $(t(126)=.59, p=.556)$. There were also no differences based on broad disciplinary group $(F(2,125)=1.85 ; p=.161)$. This finding suggests similar attitudes toward disability among the participants in our study. See Table 1 for means and standard deviations, and Table 3 for unique variance predicted by each demographic variable.

\section{Does exposure to people with disability predict post-secondary educators' attitudes toward disability?}

In order to address this question, we conducted a hierarchical linear regression analysis with overall scores on the EADS as the dependent variable. In step 1 of the regression, we added each of the demographic variables examined in the previous analyses as well as familiarity with AODA. In step 2 we entered personal experiences with disability (i.e., self, family, or friend), and finally in step 3 we added frequency of previous experience teaching students with disabilities. Table 2 shows the 


\section{Table 1}

Means (and Standard Deviations) for EADS Scores by Demographic Variables

\begin{tabular}{lcc}
\hline \multicolumn{1}{c}{ Demographic Variable } & $\mathrm{N}$ & EADS score \\
\hline $\begin{array}{l}\text { Gender } \\
\text { Male }\end{array}$ & 37 & $5.17(.46)$ \\
$\quad$ Female & 90 & $5.23(.46)$ \\
Faculty Status & & \\
$\quad$ Full-time & 87 & $5.26(.44)$ \\
$\quad$ Part-time & 41 & $5.12(.48)$ \\
Institution & & \\
$\quad$ College & $65(21 \mathrm{PT} / 44 \mathrm{FT})$ & $5.19(.49)$ \\
$\quad$ University & $63(20 \mathrm{PT} / 43 \mathrm{FT})$ & $5.24(.43)$ \\
Discipline & & $5.31(.42)$ \\
Arts, Humanities, \& Social Sciences & 54 & $5.15(.50)$ \\
Health Sciences, Science, \& Engineering & 51 & $5.16(.45)$ \\
Professional Schools & 23 & \\
\hline
\end{tabular}

Note: Professional schools includes Faculties of Business, Law, Education, and Skilled Trades.

\section{Table 2}

Means (and Standard Deviations) of EADS Scores by Familiarity with Disability

\begin{tabular}{lcc}
\hline \multicolumn{1}{c}{ Familiarity with Disability } & $\mathrm{N}$ & EADS score \\
\hline $\begin{array}{l}\text { Familiarity with AODA } \\
\text { Yes }\end{array}$ & 111 & $5.22(.47)$ \\
No & 17 & $5.21(.36)$ \\
Self, friend, or family member has disability & & \\
Yes & 64 & $5.31(.44)$ \\
No & 63 & $5.13(.47)$ \\
Frequency of students with disability in class & & \\
Always & 40 & $5.37(.44)$ \\
Often & 53 & $5.24(.38)$ \\
Sometimes or rarely & 35 & $5.00(.51)$ \\
\hline
\end{tabular}


means (and standard deviations) for EADS score by AODA and experience variables, while Table 3 shows the regression outcomes.

As shown in Table 2, most participants (87\%) reported familiarity with the AODA, but even with this highly unbalanced data set, as shown in Table 3, there was no significant effect on attitude based on familiarity with the AODA. The number of participants with a personal connection to disability was much more evenly split, with $49.6 \%$ reporting themselves, a friend, or a family member having a disability. Most of these participants reported a familial connection to disability (76\%), with only $9.5 \%$ reporting themselves as having a disability and $9.5 \%$ reporting a friend with a disability (the rest did not specify their relationship). As shown in Table 3, presence of personal connection to disability had a significant impact on attitudes, with those who have personal contact with disability reporting higher overall attitudes toward disability. This effect was significant over and above the demographic variables.

Similarly, more than $70 \%$ of professors reported that they "often" or "always" experience teaching students with disabilities and/or accommodation plans. Interestingly, there were no differences in experience depending on whether the participant was teaching at a college or university $\left(\chi^{2}(2)=2.55 ; p=.279\right)$. However, a professional connection to disability was also associated with more positive attitudes toward disability, with those reporting that they "always" or "often" have students in their classes with disabilities showing more positive attitudes than those who only encounter students with disabilities "sometimes" or "rarely" (see Table 3). This effect was significant after controlling for demographic variables as well as personal experiences. Taken together, these data suggest that exposure to disability, more than any demographic variable, accounts for more positive attitudes toward disability.

\section{Discussion}

Overall, the findings of this study suggest that professors hold very positive attitudes toward disability. In this study, positive attitudes were consistently reported by faculty at the college and university level, as well as across different academic disciplines, employment status, gender, and age. The positive scores are in line with the existing literature on post-secondary educators' atti- tudes toward disability (Lombardi \& Murray, 2011; Sniatecki et al., 2015; Stampoltzis et al., 2015). The lack of variance between groups, however, is uncharacteristic of the field of research. For example, previous studies have found some faculty from certain disciplines tend to report more positive attitudes than others (Lombardi \& Murray, 2011; Skinner, 2007) and that females generally hold more positive attitudes toward disability compared to males (Leyser et al., 1998; Lombardi \& Murray, 2011; Lombardi et al., 2013). Such differences were not observed in this study.

There are a few different ways one could interpret these findings. First, it could be argued that these positive attitudes indicate that professors do not hold ableist attitudes. There is a substantial discrepancy, however, between these findings and what students with disabilities report on this matter (e.g., Dowrick et al., 2005). Other scholars have found that attitudes do not always predict educational practices (Hansen et al., 2017; Hansen \& Dawson, 2020). In other words, there may also be inconsistencies between reported attitudes and behaviour.

The findings of this study also indicate that exposure to disability is an important factor impacting professors' attitudes toward disability. This finding is in line with the existing research on this topic (Rao, 2004). Similar trends can be observed in the $\mathrm{K}-12$ literature. For example, among children, contact with people who have disabilities has been reported as a consistent determinant factor associated with more positive attitudes toward disability (Armstrong et al., 2017; Freer, 2021; Macmillan et al., 2014). Significant differences in participants' attitudes toward disability were not observed based on whether or not they were familiar with the AODA. Although, it is noteworthy that the data was unbalanced on this variable, with the vast majority of participants reporting an awareness of the AODA. This finding is unsurprising because all of the participants would have completed AODA training as a requirement of their employment in Ontario. Personal and professional experiences with people who have disabilities, however, were associated with significantly more positive attitudes toward disability compared to those with limited experiences with disability. These findings indicate that awareness alone may be insufficient for influencing attitudes and that the faculty members' experiences with disability are important. It is encouraging to know that 


\section{Table 3}

Hierarchical Regression Analysis of Demographics, Personal Experiences, and Professional Experiences Predicting EADS Score

\begin{tabular}{|c|c|c|c|c|c|}
\hline & $\Delta \mathrm{R}^{2}$ & $\beta^{\mathrm{a}}$ & $t$-value & $p$-value & $s r^{2 b}$ \\
\hline Step 1 & .07 & & & .374 & \\
\hline Age & & -.004 & .03 & .976 & $<.001$ \\
\hline Faculty Status & & .16 & 1.63 & .105 & .02 \\
\hline Gender & & .09 & .92 & .357 & .007 \\
\hline Institution & & .11 & 1.05 & .298 & .008 \\
\hline Years Experience & & .04 & .31 & .756 & $<.001$ \\
\hline Discipline (Professional) ${ }^{c}$ & & -.14 & 1.37 & .175 & .01 \\
\hline Discipline (Sciences) ${ }^{\mathrm{C}}$ & & -.19 & 1.85 & .067 & .03 \\
\hline AODAAwareness & & .08 & .82 & .413 & .005 \\
\hline Step 2 & .05 & & & .015 & \\
\hline $\begin{array}{l}\text { Personal experience with } \\
\text { disability }\end{array}$ & & .24 & 2.48 & .015 & .05 \\
\hline Step 3 & .07 & & & .008 & \\
\hline $\begin{array}{l}\text { Professional experiences with } \\
\text { disability (often) }^{d}\end{array}$ & & .28 & 2.47 & .015 & .04 \\
\hline $\begin{array}{l}\text { Professional experiences with } \\
\text { disability (always) }^{d}\end{array}$ & & .38 & 3.11 & .002 & .07 \\
\hline
\end{tabular}

a Standardized regression coefficient.

${ }^{\mathrm{b}}$ Squared semi-partial correlation.

${ }^{c}$ Arts and Humanities acted as the comparison group for discipline.

${ }^{\mathrm{d}}$ Sometimes or rarely acted as the comparison group for professional experiences with disability.

more and more students with disabilities are attending higher education institutes and therefore it seems professors will likely be exposed to students with disabilities at greater rates in the years to come. That said, this finding poses a potential barrier for students who enter into programs with a low prevalence of students with disabilities, as these professors will likely have fewer experiences with disability. Additionally, the first student with a disability that an instructor encounters is more likely to face poorer attitudes than later students. Finally, colleges typically report having a larger proportion of students with disabilities than universities (Fichten et al.,
2003; Harrison \& Wolforth, 2012). Given that our results show that increased exposure may lead to more positive attitudes, speculatively, this lack of exposure in universities could put students in universities at greater risk of encountering ableist attitudes compared to colleges. It is important to note, however, that there were no significant differences observed between the college and university professors' attitudes toward disability in this study.

Mere Exposure Theory states that the more someone encounters an attitude object, the more positive their attitudes toward that object becomes (Zajonc, 2001). While this theory offers a possible interpretation for the 
findings, it seems that more meaningful contact and interactions with people who have disabilities account for the attitudinal differences observed, as opposed to mere exposure. Although it cannot be fully ascertained from this study, it seems the context, quality, and frequency of these experiences matter. It could be the case that these experiences help to build professors' self-efficacy for teaching students with disabilities.

\section{Recommendations}

In this section we provide recommendations for policy, practice, and future research based upon the results of this study. The major finding from this study regarding experience impacts all three types of recommendations. The results clearly point to the importance of disability experiences. Again, we found that professors' attitudes toward disability were influenced by their experiences with people who have disabilities, more than any other factor investigated in this study. The importance of the lived experiences of people who have disabilities cannot be overstated. For years, the mantra of the disability rights movement has been "nothing about us, without us." This research suggests that able-bodied policy makers, educators, and researchers may learn from the experiences of people who have disabilities.

Institutions of higher education have a responsibility to create accessible and inclusive policies for all students, including those with disabilities. In Ontario, where this study was conducted, professors are required to take AODA awareness training. This requirement is not the case everywhere and is an important step in the right direction. That said, the results of this study suggest that more can be done to break down barriers that students with disabilities face in post-secondary education. It is recommended that post-secondary institutions develop policies that extend beyond awareness training mandates and actively work toward reducing stigma and ableism. Additionally, colleges and universities should examine their programs (especially those with comparatively low enrolment of students with disabilities) to see how institutional policies and procedures (e.g., physical demand requirements) can be updated to enhance accessibility and inclusivity initiatives.

With regard to educational practice, it is clear that professors need to seek opportunities for training, especially when they feel their experiences with disability are limited. Staff in disability support offices can play a critical role in developing training on evidence-based educational practices. For example, a workshop on how to honour students' accommodation plans, or how to apply inclusive practices in the classroom (e.g., UDL principles). This training, coupled with experiences with students who have special education needs, could enhance professors' attitudes. It is possible that professors without these experiences are at a loss regarding how to support students with accommodation plans. Training is essential to help bridge that gap. It could also be beneficial to include disability experiences in such training (e.g., anonymous narratives from graduates). Caution should be exercised with such approaches and would need to be strictly voluntary. This perspective could be invaluable, but it is important to remember that it is not the students' responsibility to teach professors about disability. While authentic experiences with disability seem to be critical to professors' attitude development, it may place an undue burden on the students with disabilities, especially if their instructor has limited experiences. Providing professors with experiences with people who have disabilities (e.g., a guest speaker) before they are faced with decisions around educational practice in their classroom could help to curb potentially negative attitudes (and actions) before they arise with students.

Finally, there are gaps in this field of research that need to be addressed with subsequent studies. The results of this study differed from other studies in the field with regard to many of the determinant factors examined. Replication studies are needed to help clarify what impact these factors might have on post-secondary educators' attitudes toward disability. Additionally, the major finding of this study indicates that it may be worthwhile to take a closer look at professors' experiences with disability. For example, studies examining the types of experiences educators have had with disability and how this might impact attitude development would be beneficial. It would be interesting to investigate what impact negative, neutral, or positive experiences have on faculty members' attitudes toward disability. Diverse research approaches may help the field to better understand this phenomenon. While quantitative attitude scores offer important information, they may be subject to social desirability. A mixed method approach may allow professors to contextualize their attitude scores with narratives from their lived experiences. For example, including a qualitative component (e.g., interviews or focus groups) may 
allow participants to delve much deeper into the nature of their experiences with their students who have disabilities. Qualitative data (combined with quantitative data) might allow researchers to better understand the challenges faculty are facing with regard to supporting students with exceptionalities.

\section{Limitations}

This study had some important limitations that need to be acknowledged. The overwhelmingly positive attitudes toward disability reported by the participants in this study could be a result of social desirability or self-selection bias. Social desirability is a common limitation in attitudinal research (Haghighat, 2007). This limitation can occur when participants' responses are influenced by what they consider to be socially acceptable rather than based upon their authentic views. Self-selection bias can occur when the attitudes of those that chose to participate differ from those who did not wish to participate. It could be the case that those who participated were more interested in the topic of disability and thus held more positive attitudes. Self-selection bias is particularly problematic when there is a low response rate. The response rate for this study was difficult to assess because the data collection occurred over more than one semester and the number of potential participants could have changed, especially among part-time instructors. Based on the available data, the response rate is estimated below $10 \%$. Low response rates are common in online surveys. In addition, there was very little variance observed in this study based on the demographic factors (other than experiences with disability). This lack of variance could have been a result of a ceiling effect, where the scores were so high across all participants that it was difficult to observe differences. Additionally, the unbalanced data (e.g., with AODA awareness) could have compromised the statistical analyses. Finally, despite an adequate sample size $(n=128)$, this study was conducted with only two educational institutions from the same geographical area in southwestern Ontario, Canada. For all of these reasons, the discussion above should be interpreted with caution, as replication studies are warranted, and generalizability is limited.

\section{Conclusion}

This study investigated post-secondary educators' attitudes toward disability, determinant factors, and the role of exposure/experience with disability. We found that professors of higher education in our sample generally held positive attitudes toward disability. While this finding is promising on the surface, limitations with regard to potential social desirability and self-selection bias were discussed. Additionally, little variance was found with regard to determinant factors (e.g., discipline, age, gender, etc.). Personal and professional experiences with disability, however, were found to be significantly associated with more positive attitudes toward disability compared to those who did not have experiences such as these.

Faculty members' attitudes toward disability can impact the experiences of students with special education needs in post-secondary institutions. With more students who have disabilities attending post-secondary education, faculty have a responsibility to examine their preconceived notions around ability and disability. Based on the findings of this study, it seems that the more experience a professor has with students who have disabilities, the more positive their attitudes become. As professors acquire more experience with disability and their attitudes toward it improve, so too should the educational experiences of students with disabilities. Breaking down attitudinal barriers is a key step toward educational and employment equity. Including those with disability experiences should be at the forefront of inclusivity efforts in post-secondary institutions.

\section{References}

Ajzen, I. (1985). From intentions to actions: A theory of planned behaviour. In J. Kuhl \& J. Beckmann (Eds.), Action control: From cognition to behaviour (pp. 11-39). Springer.

Ajzen, I. (2001). Nature and operation of attitudes. Annual Review of Psychology, 52, 27-58. https:ll doi.org/10.1146/annurev.psych.52.1.27

AODAAlliance. (2020). What barriers do students with disabilities face in post-secondary education in Ontario? https://www.aodaalliance.org/whats-new/ what-barriers-do-students-with-disabilities-facein-post-secondary-education-in-ontario-send-us- 
feedback-on-our-draft-framework-for-a-post-secondary-education-accessibility-standard/

Armstrong, M., Morris, C., Abrahman, C., \& Tarrant M. (2017). Interventions utilising contact with people with disabilities to improve children's attitudes toward disability: A systematic review and meta-analysis. Disability and Health Journal, 10(1), 11-22. https://doi.org/10.1016/j.dhjo.2016.10.003

Blanca, M. J., Alarcón, R., Arnau, J., Bono, R., \& Bendayan, R. (2017). Non-normal data: Is ANOVA still a valid option? Psicothema, 29(4), 552-557. https:// doi.org/10.7334/psicothema2016.383

Buchanan, T., St. Charles, M., Rigler, M., \& Hart, C. (2010). Why are older faculty members more accepting of students with attention-deficit hyperactivity disorder? A life-course interpretation. International Journal of Disability, Development and Education, 57(4), 35-369. https://doi.org/10.1080/1 034912X.2010.524407

Carroll, J. M., Pattison, E., Muller, C., \& Sutton, A. (2020). Barriers to bachelor degree completion among college students with a disability. Sociological Perspectives, 63(5), 809-832. https://doi. org/10.1177/0731121420908896

de Boer, A., Pijl, S. J., \& Minnaert, A. (2012). Students' attitudes towards peers with disabilities: A review of the literature. International Journal of Disability, Development and Education, 59(4), 379-392. https://doi.org/10.1080/1034912X.2012.723944

Dowrick, P. W., Anderson, J., Heyer, K., \& Acosta, J. (2005). Postsecondary education across the USA: Experiences of adults with disabilities. Journal of Vocational Rehabilitation, 22(1), 41-47. https:ll content.iospress.com/articles/journal-of-vocational-rehabilitation/jvr00272

Duquette, C. (2000). Experiences at university: Perceptions of students with disabilities. The Canadian Journal of Higher Education, 30(2), 123-142. https://journals.sfu.ca/cjhe/index.php/cjhe/article/ view/183359

Festinger, L. (1957). A theory of cognitive dissonance. Stanford University.

Fichten, C. S., Jennison, V. A., Barile, M., Robillard,
C., Fossey, M. E., \& Lamb, D. (2003). Canadian postsecondary students with disabilities: Where are they? The Canadian Journal of Higher Education, 33(3), 71-114. https://journals.sfu.ca/cjhe/index. php/cjhe/article/view/183441

Fishbein, M. (1963). An investigation of the relationship between beliefs about an object and the attitude toward that object. Human Relations, 16, 233-239. https://doi.org/10.1177/001872676301600302

Francis, G. L., Duke, J. M., Fujita, M., \& Sutton, J. C. (2019). "It's a constant fight:" Experiences of college students with disabilities. Journal of Postsecondary Education and Disability, 32(3), 247-261. https://eric.ed.gov/?id=EJ1236871

Freer, J. (2018). The Educators' Attitude toward Disability Scale (EADS): A pilot study. International Journal of Disability, Development, and Education, 65(6), 581-598. https://doi.org/10.1080/103491 2X.2018.1426098

Freer, J. (2021). Students' attitudes toward disability: A systematic literature review. International Journal of Inclusive Education. Advance article. https://doi.org L10.1080/13603116.2020.1866688

Gawronski, M., Kuk, L., \& Lombardi, A. R. (2016). Inclusive instruction: Perceptions of community college faculty and students pertaining to universal design. Journal of Postsecondary Education and Disability, 29(4), 331-347. https://eric.ed.gov/?id=EJ1133816

Haghighat, R. (2007). The development of the Brief Social Desirability Scale (BSDS). Europe's Journal of Psychology, 3(4). https://doi.org/10.5964/ejop. v3i4.417

Hansen, K. D., \& Dawson, D. L. (2020). "We can do better": Community college faculty preparedness for teaching students with learning disabilities. Journal of Diversity in Higher Education, 13(4), 309-319. https://doi.org/10.1037/dhe0000142

Hansen, K. D., Dawson, D. L., \& Specht, J. A. (2017). Faculty preparedness to teach students with learning disabilities: Developing an instrument to assess faculty perceptions. Exceptionality Education International, 27, 99-115. https://ir.lib.uwo.ca/ eei/vol27/iss $1 / 6$ 
Harrison, A. G., \& Wolforth, J. (2012). Findings from a pan-Canadian survey of disability services providers in postsecondary education. The International Journal of Disability, Community and Rehabilitation, 11(1). http://www.ijdcr.ca/VOL11 01/articles/ harrison.shtml

Jensen, J. M., McCrary, N., Krampe, K., \& Cooper, J. (2004). Trying to do the right thing: Faculty attitudes toward accommodating students with learning disabilities. Journal of Postsecondary Education and Disability, 17(2), 81-90. https://eric.ed.gov L?id=EJ876004

Koo, K. (2017). An examination of faculty attitudes and willingness to accommodate students with disabilities at the University of Saskatchewan (Master's thesis, University of Saskatchewan). University of Saskatchewan HARVEST Repository. https://harvest.usask.ca/handle/10388/7801

Kutscher, E. L., \& Tuckwiller, E. D. (2019). Persistence in higher education for students with disabilities: A mixed systematic review. Journal of Diversity in Higher Education, 12(2), 136-155. https://doi. org/10.1037/dhe0000088

Levey, J. A. (2014). Attitudes of nursing faculty toward nursing students with disabilities: An integrative review. Journal of Postsecondary Education and Disability, 27(3), 321-332. https://eric.ed.gov ? ?id=EJ1048784

Leyser, Y., Vogel, S., Wyland, S., \& Brulle, A. (1998). Faculty attitudes and practices regarding students with disabilities: Two decades after implementation of Section 504. Journal of Postsecondary Education and Disability, 13(3), 5-19. https://www.ahead. org/professional-resources/publications/jped/archived-jped/jped-volume-13

Lombardi, A. R., \& Murray, C. (2011). Measuring university faculty attitudes toward disability: Willingness to accommodate and adopt universal design principles. Journal of Vocational Rehabilitation, 34(1), 43-56. https://doi.org/10.3233/JVR-2010-0533

Lombardi, A., Murray, C., \& Dallas, B. (2013). University faculty attitudes toward disability and inclusive instruction: Comparing two institutions. Journal of Postsecondary Education and Disability, 26(3),
221-232. https://eric.ed.gov/?id=EJ1026882

Macmillan, M., Tarrant, M., Abraham, C., \& Morris, C. (2014). The association between children's contact with people with disabilities and their attitudes towards disability: A systematic review. Developmental Medicine and Child Neurology, 56(6), 529-546. https://doi.org/10.1111/dmcn.12326

Malone, C. R. (2021). The effect of background experience on school counselor self-efficacy when working with students with disabilities (Doctoral dissertation, George Washington University). GW ScholarSpace. https://scholarspace.library.gwu.edul etd/9s1616962

McCloy, U., \& DeClou, L. (2013) Disability in Ontario: Postsecondary education participation rates, student experience and labour market outcomes. Higher Education Quality Council of Ontario. https://heqco.ca/wp-content/uploads/2020/03/At-Issue-Disability-in-ON_ENG.pdf

National Educational Association of Disabled Students. (2012). Enhancing accessibility in post-secondary education institutions: A guide for disability service providers. https://www.neads.ca/en/norc/eag/ eag_en.pdf

National Educational Association of Disabled Students. (2018). Landscape of accessibility and accommodation in post-secondary education for students with disabilities. https://www.neads.ca/en/ about/media/AccessibilityandAccommodation $\% 20$ 2018-5landscapereport.pdf

Oliver, M. (1996). Understanding disability: From theory to practice. Macmillan.

Ontario Human Rights Commission. (n.d.). Post-secondary education. http://www.ohrc.on.ca/en/ opportunity-succeed-achieving-barrier-free-education-students-disabilities/post-secondary-education\#fn105

Ostrovsky, Y., \& Frenette, M. (2015). The cumulative earnings of postsecondary graduates over 20 years: Results by field of study. Statistics Canada. https://www150.statcan.gc.ca/n1/pub/11-626-x/11626-x2014040-eng.htm

Rao, S. (2004). Faculty attitudes and students with 
disabilities in higher education: A literature review. College Student Journal, 38(2), 191-198. https:/l psycnet.apa.org/record/2004-16679-004

Skinner, M. E. (2007). Faculty willingness to provide accommodations and course alternatives to postsecondary students with learning disabilities. International Journal of Special Education, 22(2), 32-45. https://eric.ed.gov/?id=EJ814486

Sniatecki, J. L., Perry, H. B., \& Snell, L. H. (2015). Faculty attitudes and knowledge regarding college students with disabilities. Journal of Postsecondary Education and Disabilities, 28(3), 259-275. https:/l eric.ed.gov/?id=EJ1083837

Stampoltzis, A., Tsitsou, E., Plesti, H., \& Kalouri, R. (2015). Lecturer perspectives in dyslexia within one Greek university: A pilot study. Electronic Journal of Research in Educational Psychology, 13(3), 587-606. https://doi.org/10.14204/ejrep.37.15002

Triandis, H. C. (1971). Attitude and attitude change. Wiley.

Tsagris, D., \& Muirhead, B. (2012). Evaluating postsecondary supports for Ontario students with learning disabilities. Higher Education Quality Council of Ontario. https://heqco.ca/wp-content/ uploads/2020/03/EvaluatingPSESupportsForStudentsWithLearningDisabilities.pdf

Turcotte, M. (2014). Persons with disabilities and employment. Statistics Canada: Insights on Canadian Society. https://www150.statcan.gc.ca/n1/en/ pub/75-006-x/2014001/article/14115-eng.pdf?st=isB78XxS

Wynants, S. A., \& Dennis, J. M. (2017). Embracing diversity and accessibility: A mixed methods study of the impact of an online disability awareness program. Journal of Postsecondary Education and Disability, 30(1), 33-48. https://eric.ed.gov/?id=EJ1144611

Zajonc, R. B. (1980). Feeling and thinking: Preferences need no inferences. American Psychologist, 35, 151-175. https://doi.org/10.1037/0003$\underline{066 \times .35 .2 .151}$

Zajonc, R. B. (2001). Mere exposure: A gateway to the subliminal. Current Directions in Psychological Science, 10(6), 224-228. https://doi.org/10.1111/1467$\underline{8721.00154}$

\section{Contact Information}

John Freer

jfreer@stclaircollege.ca

jfreer@uwindsor.ca 